\title{
Coexistence of multiple coronaviruses in several bat colonies in an abandoned mineshaft
}

\author{
Xing-Yi Ge ${ }^{1 \#}$, Ning Wang ${ }^{1 \#}$, Wei Zhang ${ }^{1}$, Ben Hu${ }^{1}$, Bei Li ${ }^{1}$, Yun-Zhi Zhang ${ }^{2,3}$, Ji-Hua Zhou ${ }^{2}$, \\ Chu-Ming Luo ${ }^{1}$, Xing-Lou Yang ${ }^{1}$, Li-Jun Wu ${ }^{1}$, Bo Wang ${ }^{1}$, Yun Zhang ${ }^{4}$, Zong-Xiao Li ${ }^{4}$, Zheng-Li Shi ${ }^{1 凶}$ \\ 1. Key Laboratory of Special Pathogens, Wuhan Institute of Virology, Chinese Academy of Sciences, \\ Wuhan 430071, China \\ 2. Yunnan Provincial Key Laboratory for Zoonosis Control and Prevention, Yunnan Institute of Endemic \\ Diseases Control and Prevention, Dali 671000, China \\ 3. School of Public Health, Dali University, Dali 671000, China \\ 4. Mojiang Center for Diseases Control and Prevention, Mojiang 654800, China
}

Since the 2002-2003 severe acute respiratory syndrome (SARS) outbreak prompted a search for the natural reservoir of the SARS coronavirus, numerous alpha- and betacoronaviruses have been discovered in bats around the world. Bats are likely the natural reservoir of alpha- and betacoronaviruses, and due to the rich diversity and global distribution of bats, the number of bat coronaviruses will likely increase. We conducted a surveillance of coronaviruses in bats in an abandoned mineshaft in Mojiang County, Yunnan Province, China, from 2012-2013. Six bat species were frequently detected in the cave: Rhinolophus sinicus, Rhinolophus affinis, Hipposideros pomona, Miniopterus schreibersii, Miniopterus fuliginosus, and Miniopterus fuscus. By sequencing PCR products of the coronavirus RNA-dependent RNA polymerase gene (RdRp), we found a high frequency of infection by a diverse group of coronaviruses in different bat species in the mineshaft. Sequenced partial RdRp fragments had $80 \%-99 \%$ nucleic acid sequence identity with well-characterized Alphacoronavirus species, including BtCoV HKU2, BtCoV HKU8, and BtCoV1, and unassigned species BtCoV HKU7 and BtCoV HKU10. Additionally, the surveillance identified two unclassified betacoronaviruses, one new strain of SARS-like coronavirus, and one potentially new betacoronavirus species. Furthermore, coronavirus co-infection was detected in all six bat species, a phenomenon that fosters recombination and promotes the emergence of novel virus strains. Our findings highlight the importance of bats as natural reservoirs of coronaviruses and the potentially zoonotic source of viral pathogens.

\section{KEYWORDS coronavirus; bat; coinfection; mineshaft}

\section{INTRODUCTION}

Coronaviruses are divided into the genera Alphacoronavirus, Betacoronavirus, Gammacoronavirus, and a proposed Deltacoronavirus genus (Woo et al., 2012a), and belong

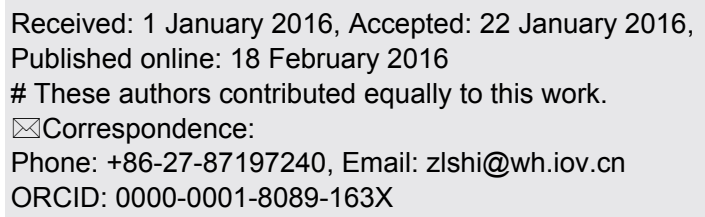

to the subfamily Coronavirinae, family Coronaviridae, of the order Nidovirales. Alphacoronaviruses infect pigs (Kusanagi et al., 1992), humans (Macnaughton and Madge, 1978; van der Hoek et al., 2004), cats (Pedersen et al., 1984), bats (Poon et al., 2005), and other mammals. Betacoronaviruses infect humans (Bruckova et al., 1970; Peiris et al., 2003; Woo et al., 2005; Zaki et al., 2012), mice (Mizutani, 2001), bats (Li et al., 2005), and other mammals. Gammacoronaviruses mostly infect birds though some infect sea mammals (Mihindukulasuriya et al., 2008; Woo et al., 2012a). The proposed 
deltacoronaviruses primarily infect birds but are also reported to infect mammals (Woo et al., 2012a).

Human coronaviruses used to have low pathogenicity and cause mild respiratory symptoms. However, two coronaviruses, severe acute respiratory syndrome coronavirus (SARS-CoV) (Peiris et al., 2003) and Middle East respiratory syndrome coronavirus (MERS-CoV), can cause severe respiratory diseases (Zaki et al., 2012). Phylogenetic evidence indicates that SARS-CoV and MERS-CoV originated from bats (van Boheemen et al., 2012; Ge et al., 2013; Lau et al., 2013). Since the 2002-2003 outbreak of SARS in China, coronaviruses have been discovered in 71 bat species throughout Asia, America, Africa, and Europe (Tang et al., 2006; Lau et al., 2012; Woo et al., 2012b; Anthony et al., 2013; De Benedictis et al., 2013; Geldenhuys et al., 2013; Goes et al., 2013; Graham et al., 2013; Lelli et al., 2013; Shi, 2013). Among the 15 established alpha- and betacoronavirus species, eight were identified in bats in China, including Miniopterus bat coronavirus 1 (BtCoV 1), Miniopterus bat coronavirus HKU8 (BtCoV HKU8), Rhinolophus bat coronavirus HKU2 (BtCoV HKU2), Scotophilus bat coronavirus 512 (BtCoV 512), SARS-related or SARS-like CoVs (SL-CoV; WIV1, Rp3, HKU3, etc.), Pipistrellus bat coronavirus HKU5 (BtCoV HKU5), Rousettus bat coronavirus HKU9 (BtCoV HKU9), and Tylonycteris bat coronavirus HKU4 (BtCoV HKU4) (Lau et al., 2005; Li et al., 2005; Woo et al., 2006; Lau et al., 2007; Chu et al., 2008; Woo et al., 2009; Cavanagh and Britton, 2012; Woo et al., 2012b). Viruses similar to the above bat coronavirus species or strains $(\mathrm{BtCoV} 1$, HKU2, HKU9, 512, HKU8, and SL-CoV) have been found in southeast Asia and Europe (Watanabe et al., 2010; Gouilh et al., 2011; Wacharapluesadee et al., 2015; Drexler et al., 2010; Lelli et al., 2013).

Considering the species diversity and geographical distribution of bats, it is likely that novel bat coronaviruses remain to be discovered. Furthermore, continuous surveillance of bat coronaviruses will provide insights into the evolution of coronaviruses as well as help in evaluating the potential for interspecies transmission of these viruses from bats to humans and other animals (Drexler et al., 2011). In this study, we conducted a twoyear RT-PCR surveillance of bat coronaviruses in an abandoned mineshaft in Mojiang County, Yunnan Province, China. We found a high infection rate with a genetically diverse array of coronaviruses in different bat species in the mineshaft.

\section{MATERIALS AND METHODS}

\section{Sample collection and viral RNA extraction}

Bat fecal swabs were collected in August and September of 2012 and in April and July of 2013 as described previ- ously (Li et al., 2005). The collected samples were kept in viral transport medium $(1 \times$ Hank's balanced salt solution, $1 \%$ bovine albumin, $\mathrm{pH} 7.4,15 \mu \mathrm{L} / \mathrm{mL}$ amphotericin $\mathrm{B}, 100$ units $/ \mathrm{mL}$ penicillin $\mathrm{G}$ and $50 \mathrm{ug} / \mathrm{mL}$ streptomycin) and stored at $-80{ }^{\circ} \mathrm{C}$ before processing. The bat species were first identified based on morphology. PCR amplification and sequencing of cytochrome $\mathrm{b}(\mathrm{Cytb})$ or NADH dehydrogenase subunit 1 (ND1) (Irwin et al., 1991; Mayer and von Helversen, 2001) from DNA extracted from the fecal swabs was used to confirm the bat species. Viral RNA was extracted from $140 \mu \mathrm{L}$ of the fecal swab samples with Viral RNA Mini Kit (Qiagen, Westburg, The Netherlands) per the manufacturer's instructions. RNA was eluted in $60 \mu \mathrm{L}$ of AVE (RNasefree water with $0.04 \%$ sodium azide) buffer, aliquoted, and stored at $-80^{\circ} \mathrm{C}$.

\section{PCR screening of coronaviruses and sequencing} One-step RT-PCR (Invitrogen, San Diego, USA) was used for the amplification of a 440-bp fragment targeting the RNA-dependent RNA polymerase gene ( $R d R p)$ of all known alpha- and betacoronaviruses (de Souza Luna et al., 2007). Amplification of an 816-bp fragment extending the $440 \mathrm{bp}$ was performed using published methods (Drexler et al., 2010). Spike $(S)$ genes were amplified using degenerate primers designed based on the alignment of known coronaviruses (sequences provided upon request). Standard precautions were taken to avoid PCR contamination, and no false positives were observed in negative controls. PCR products were gelpurified and sequenced on the ABI PRISM ${ }^{\circledR} 3100$ Genetic Analyzer (Applied Biosystems, Foster City, USA). The sequencing chromatograms were carefully inspected for overlapping multicolor peaks, which are an indicator of sequence heterogeneity in the amplicons. The PCR products of corresponding samples were cloned and 10 clones of each sample were sequenced to confirm sequence heterogeneity. To avoid PCR contamination, all positive samples were checked through two independent PCRs by different experimenters. The positive samples detected in this study were named using the abbreviated bat species name plus the bat sample number abbreviation. For example, a virus detected from Rhinolophus sinicus in sample number 4017 was named RsBtCoV/4017. If the bat was co-infected by two different coronaviruses, numbers were appended to the sample names, such as RsBtCoV/4017-1 and RsBtCoV/4017-2.

\section{Sequence analysis}

Preliminary sequence management and analysis were carried out using Geneious (version 5.5.9, Biomatters Limited, New Zealand), sequence alignment and editing were performed using ClustalW (version 2.0) and BioEdit (version 7.1.9) (Hall, 1999; Larkin et al., 2007). Poten- 
tial in vitro recombinant sequences (i.e., PCR artifacts) were screened for and discarded using Recombination Detection Program v2.0 (Martin et al., 2005). Obtained consensus sequences were compared with known sequences of the coronavirus $R d R p$ genes in GenBank. Phylogenetic trees were constructed using MrBayes (version 3.2) under the GTR model and the Maximum Likelihood algorithm in Geneious (Huelsenbeck and Ronquist, 2001).

\section{RESULTS}

\section{Bat species identification}

In total, 276 bats (83 in August 2012; 97 in September 2012; 52 in April 2013, and 44 in July 2013) were sampled in a mineshaft in Mojiang (Figure 1). Six bat species were identified based on morphology and confirmed by sequencing of the Cytb or ND1 gene (Table 1). Bat species or most closely related species were $R$. sinicus, Rhinolophus affinis, Hipposideros pomona, Miniopterus schreibersii, Miniopterus fuliginosus, and Miniopterus fuscus. Full-length $C y t b$ and ND1 gene sequences were deposited in GenBank under accession numbers KP876547 to KP876557.

\section{Detection of CoVs in bats}

Among the collected 276 fecal samples, 138 (50\%) were positive for coronavirus: $45.7 \%$ (37/81) in August and $74.7 \%(74 / 99)$ in September 2012, and 46.2\% (24/52) in

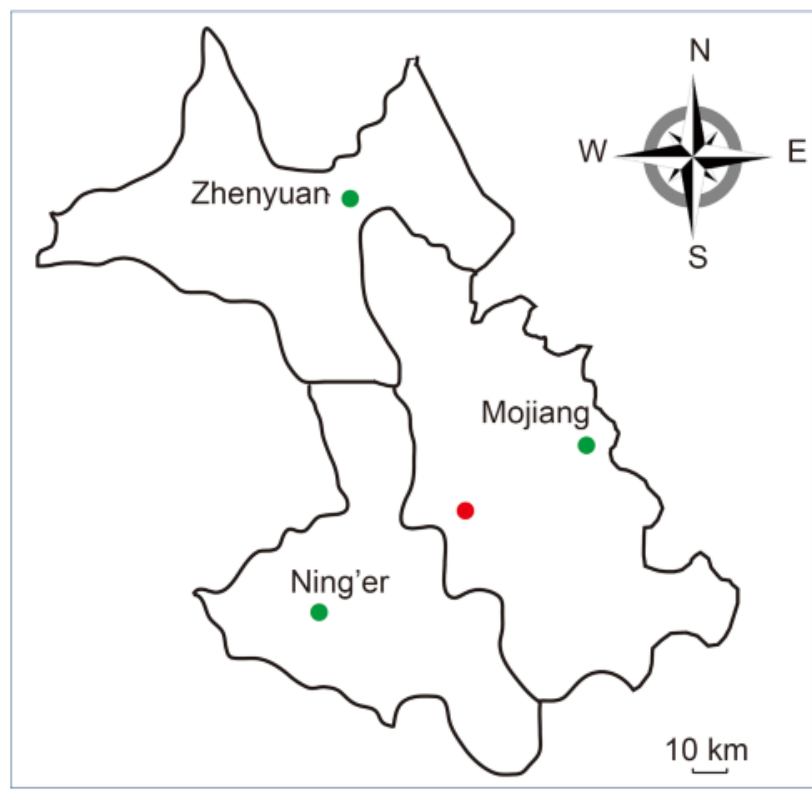

Figure 1. Sample collection site in Mojiang, Yunnan Province. The mineshaft where bat samples were collected is indicated with a red dot, three county towns (Mojiang, Zhenyuan, and Ning'er) near the mineshaft are labeled with green dots.
April and 6.8\% (3/44) in July 2013. All six bat species showed high infection rates, from $35 \%$ to $73 \%$ (Table 1 ). $R$. sinicus, $R$. affinis, and M. schreibersii were observed to have the highest infection rates in September 2012. Due to the small sample size, it was not possible to accurately assess changes in the infection rate for $H$. pomona, M. fuliginosus, and $M$. fuscus.

From the 138 positive samples, $152 R d R p$ partial coronavirus sequences (approximately $400 \mathrm{bp}$ ) were obtained, indicating co-infections of two viruses. Two sequences (HiBtCoV/3740-2 and $\mathrm{RaBtCoV} / 4991)$ were homologous to betacoronaviruses, all other $150 \mathrm{se}-$ quences were homologous to alphacoronaviruses, including the established bat coronavirus species BtCoV 1, Bt$\mathrm{CoV}$ HKU2, and BtCoV HKU8, unassigned BtCoV HKU7 and BtCoV HKU10, and unclassified alphacoronavirus (Table 2, Figure 2). To better understand the phylogenetic relationships between these bat coronaviruses, we selected 12 samples representing different branches of the tree and extended the sequence of the partial $R d R p$ screening fragment to $816 \mathrm{bp}$ (Figure 3). The partial $R d R p$ sequences obtained in this study were submitted to GenBank under accession numbers KP876505 to KP876546 and KU343189 to KU343200.

\section{Alphacoronaviruses detected in bats}

Among the $150 R d R p$ partial sequences that were homologous to alphacoronaviruses, fifty-one were related to $\mathrm{BtCoV} 1$, thirty-seven to $\mathrm{BtCoV}$ HKU2, one to BtCoV HKU7, fifty-one to $\mathrm{BtCoV} \mathrm{HKU}$, four to $\mathrm{BtCoV}$ HKU10, and four to unclassified alphacoronaviruses (Table 2). Most sequences shared $87 \%-98 \%$ nucleotide (nt) identity and 95\%-100\% amino acid (aa) identity with the established bat coronavirus species, suggesting that some of these coronaviruses represent different strains of known viral species. Only a few sequences were related to unclassified bat coronaviruses. One of two sequences detected in a $R$. affinis bat (RaBtCoV/4307-1) was related to an unclassified alphacoronavirus Hipposideros BtCoV Ratcha-67/THA/2007 detected in Thailand, with $83 \%$ nt and $92 \%$ aa identities, based on the 816-bp sequence (Figure 3) (Gouilh et al., 2011). Three sequences (one in M. fuliginosus and two in R. sinicus) were related to another unclassified alphacoronavirus Cardioderma BtCoV Kenya/KY43/2006 detected in Kenya, with $80 \%$ nt and $93 \%$ aa identities (Tong et al., 2009).

\section{Betacoronaviruses detected in bats}

Only two sequences detected in this study were homologous to betacoronaviruses. One of them (RaBtCoV/4991) was detected in a $R$. affinis sample and was related to SL-CoV. The conserved 440-bp RdRp fragment of RaBt$\mathrm{CoV} / 4991$ had $89 \%$ nt identity and $95 \%$ aa identity with SL-CoV Rs672 (Yuan et al., 2010). In the phylogenetic 
Table 1. Coronavirus infection in six bat species sampled in an abandoned mineshaft in Mojing County, Yunnan Province, China from 2012 to 2013.

\begin{tabular}{llllll}
\hline \multirow{2}{*}{ Bat species } & \multicolumn{5}{c}{ No. positive/tested (\%) } \\
\cline { 2 - 5 } & Aug, 2012 & Sep, 2012 & Apr, 2013 & Jul, 2013 & No. co-infection \\
\hline Rhinolophus sinicus & $4 / 11(36)$ & $14 / 19(74)$ & $1 / 4(25)$ & $0 / 11(0)$ & $3 / 45(6.7)$ \\
Rhinolophus affinis & $4 / 15(27)$ & $7 / 17(41)$ & $21 / 43(49)$ & $2 / 31(6)$ & $1 / 106(1)$ \\
Hipposideros pomona & $3 / 3(100)$ & $0 / 1(0)$ & $0 / 2(0)$ & $1 / 2(50)$ & $1 / 8(12)$ \\
Miniopterus schreibersii & $13 / 29(45)$ & $50 / 57(88)$ & - & - & $5 / 86(6)$ \\
Miniopterus fuliginosus & $13 / 23(56)$ & - & $2 / 3(67)$ & - & $3 / 26(11)$ \\
Miniopterus fuscus & - & $3 / 5(60)$ & - & - & $1 / 5(20)$ \\
\hline
\end{tabular}

Table 2. Closely related coronavirus species detected in different bat species.

\begin{tabular}{|c|c|c|c|c|c|c|c|}
\hline \multirow{2}{*}{\multicolumn{2}{|c|}{ Coronavirus species }} & \multicolumn{6}{|c|}{ Bat species and number of individuals in which coronaviruses were detected } \\
\hline & & R. sinicus & R. affinis & H. pomona & M. & M. fuliginosus & M. fuscus \\
\hline \multirow{5}{*}{ Alpha-CoV } & 1 & 3 & - & - & 28 & 12 & - \\
\hline & $H K U 2$ & 6 & 29 & - & - & - & - \\
\hline & HKU7 & - & - & - & 1 & - & - \\
\hline & HKU8 & 7 & 4 & - & 29 & - & 2 \\
\hline & HKU10 & - & - & 3 & - & - & - \\
\hline \multirow[t]{3}{*}{ Beta-CoV } & SARS-related & - & 1 & - & - & - & - \\
\hline & 1/HKU8 & 1 & - & - & 5 & 3 & - \\
\hline & $\begin{array}{l}\text { HKU8/ } \\
\text { Unclassified } \\
\text { alphaCoV }\end{array}$ & 1 & - & - & - & - & 1 \\
\hline \multirow[t]{2}{*}{ Co-infection } & $\begin{array}{l}\text { HKU2I } \\
\text { Unclassified } \\
\text { alphaCoV }\end{array}$ & 1 & 1 & - & - & - & - \\
\hline & $\begin{array}{l}\text { HKU10I } \\
\text { Unclassified } \\
\text { betaCoV }\end{array}$ & - & - & 1 & - & - & - \\
\hline
\end{tabular}

Note: 1, Miniopterus bat coronavirus 1; HKU2, Rhinolophus bat coronavirus HKU2; HKU8, Miniopterus bat coronavirus HKU8; SARS-related, SARS-related coronavirus; HKU7, Miniopterus bat coronavirus HKU7, unassigned; HKU10, bat coronavirus HKU10, unassigned.

tree, $\mathrm{RaBtCoV} / 4991$ showed more divergence from human SARS-CoV than other bat SL-CoVs and could be considered as a new strain of this virus lineage (Figure 2). Another sequence (HpBtCoV/3740-2) was detected in a $H$. pomona sample and shared the closest similarity $(81 \%$ and $89.1 \%$ identities at $\mathrm{nt}$ and aa levels, respectively, based on the 816-bp sequence) with a Hipposideros bat coronavirus Hipposideros/GhanaBoo/348/2008 discovered in Ghana (Quan et al., 2010). These two strains, together with Zaria bat ZBCoV (host Hipposideros commersoni) and Thailand bat BtCoV/B56054 (host Hipposideros larvatus) (Tong et al., 2009; Wacharapluesadee et al., 2015), formed an independent lineage distantly related to SL-CoVs (Figure 2,3). The partial $R d R p$ sequences of this lineage shared less than $90 \%$ aa identity compared to the closest CoVs in lineage B and thus, this lineage may represent a novel betacoronavirus species.

\section{Co-infections of coronaviruses}

Co-infection with different coronavirus species was found in 14 out of 138 positive specimens. Co-infection events were detected in all six bat species (Table 2, Figure 2). The most frequent co-infections were with the Bt$\mathrm{CoV} 1 \mathrm{~B}$ and $\mathrm{BtCoV}$ HKU8 lineages, as found previously by Chu et al. (2008). The other co-infections involved BtCoV HKU8 or BtCoV HKU2 and the unclassified bat alphacoronaviruses. Most interestingly, we also 


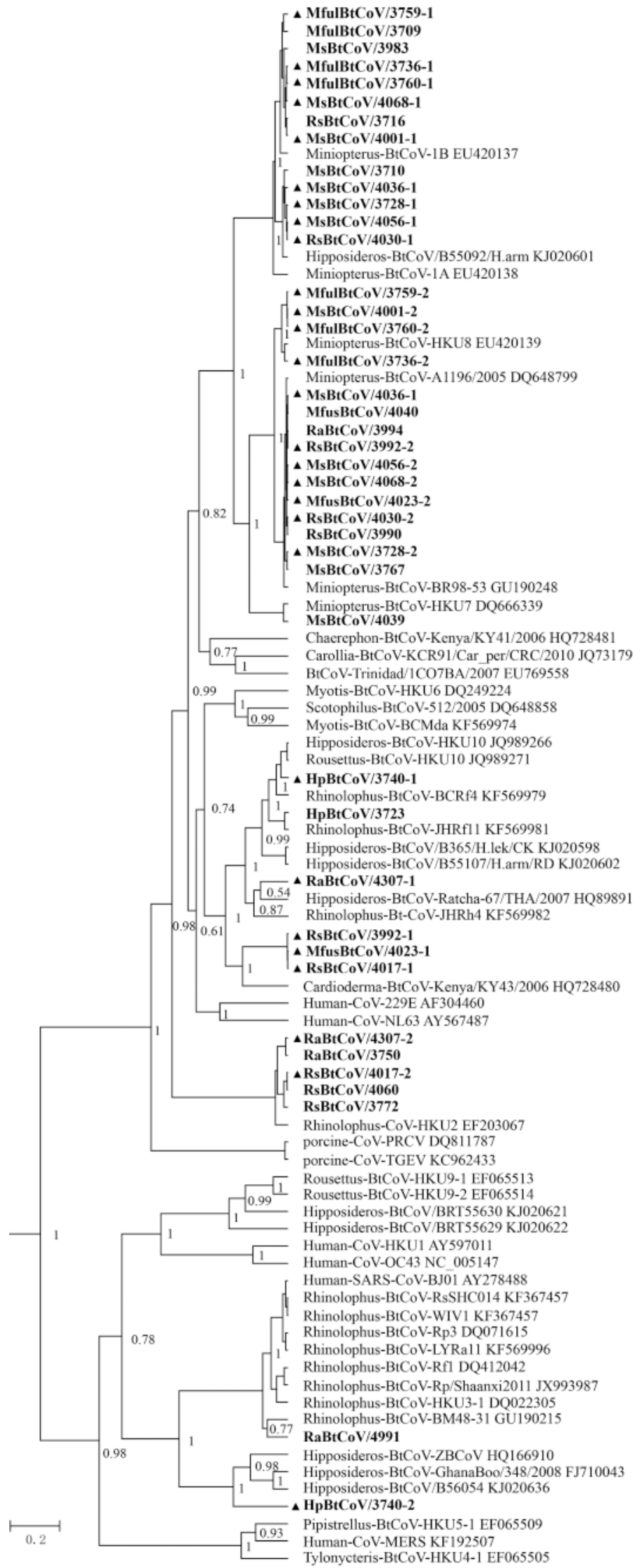

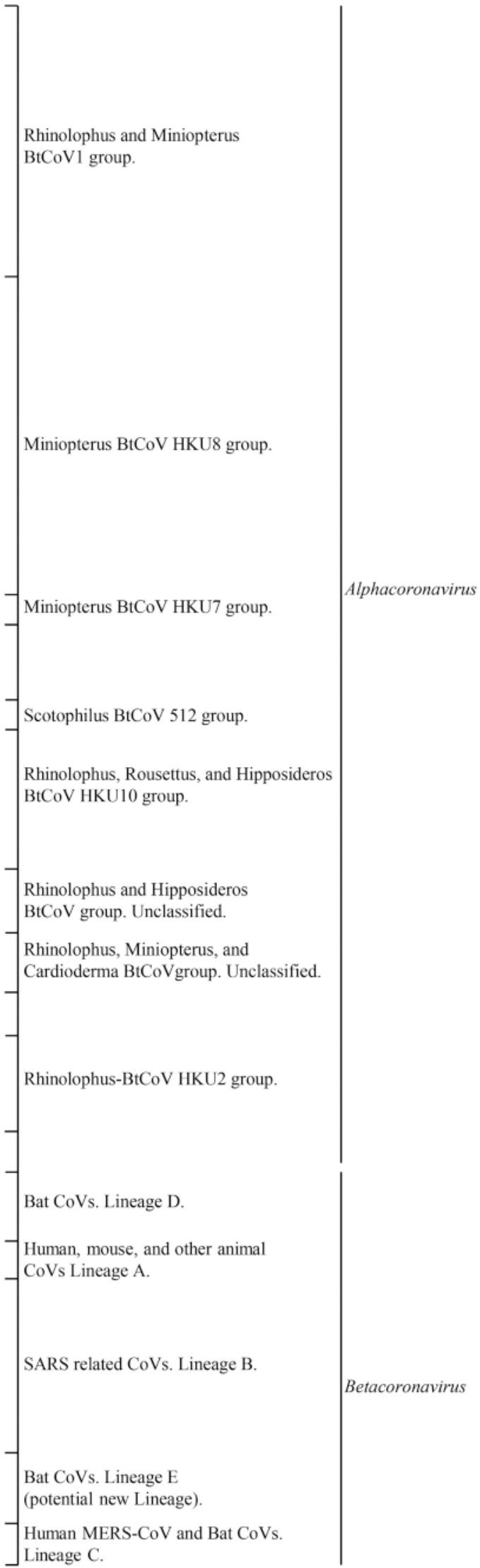


Figure 2. Phylogenetic analysis of bat coronaviruses detected in this study based on the partial RdRp gene sequences. The partial $R d R p$ gene sequences ( $370 \mathrm{bp}$ ) obtained in this study were aligned with those of known representative coronaviruses and used to construct the phylogenetic tree by MrBayes V3.2 under assumption of GTR model, using $1,000,000$ trees sampled every 100 steps, annotated with a burn-in of $90 \%$ using TreeAnnotator V1.0.6. Detected coronaviruses were classified into seven alphacoronavirus groups and two betacoronavirus lineages separated with horizontal lines. Coronaviruses co-infecting an individual are indicated by sequential number after the name of each strain. All the detected coronaviruses here are in bold and co-infection coronaviruses are labeled with a black triangle to the left of the name.

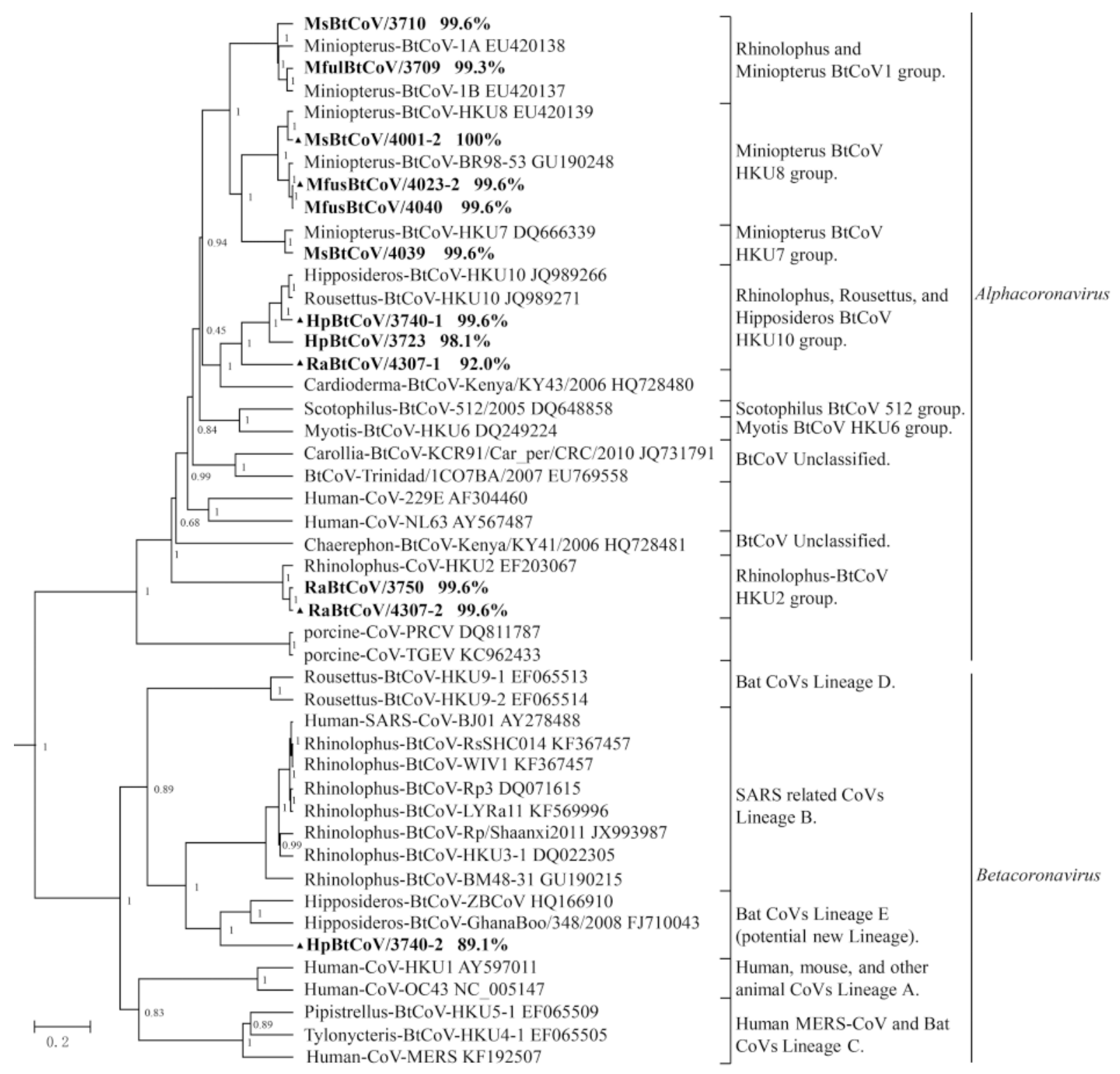

Figure 3. Phylogenetic analysis of coronaviruses based on the amino acid sequences of the partial (816-bp) $R d R p$ gene. Sequences obtained in this study were aligned with those of known representative coronaviruses and used to construct the phylogenetic tree using MrBayes. Coronaviruses co-infecting an individual are indicated with a sequential number after the name of each strain. The aa identities between coronavirus sequences detected in this study and the closest reference sequence are labeled following the virus names. The coronaviruses detected in this study are in bold and co-infecting viruses are labeled with a black triangle to the left of the sample name. 
found a co-infection with coronavirus species from two different genera, BtCoV HKU10 and an unclassified betacoronavirus in one H. pomona bat (no. 3740).

\section{Interspecies infections of bat coronaviruses}

We detected high interspecies host diversity, with the same coronavirus species infecting different bat species within and/or across families. BtCoV 1 was detected in three out of six bat species of two families (Vespertilionidae and Rhinolophidae), including M. schreibersii, $M$. fuliginosus, and R. sinicus. BtCoV HKU2 was detected in two closely related species of the same family, $R$. sinicus, and $R$. affinis. BtCoV HKU8 was detected in five out of six bat species of two families, including $M$. schreibersii, M. fuliginosus, M. fuscus, $R$. sinicus, and $R$. affinis.

To further address interspecies infections of coronaviruses in bats, we amplified 8 full-length $S$ genes from Bt$\mathrm{CoV}$ 1-positive samples including $M$. schreibersii, $M$. fuliginosus, and $R$. sinicus. The full-length $S$ genes ranged from 4,125 to 4,137 bp (Supplementary Table S1). In the phylogenetic tree, MfulBtCoV/3759-1, MsBtCoV/40681, MfulBtCoV/3736-1, MsBtCoV/4001-1, MfulBtCoV/ 3709 , and $\mathrm{RsBtCoV} / 3716$ clustered with $\mathrm{BtCoV} 1 \mathrm{~B}$, and $\mathrm{MsBtCoV} / 4056-1$ and MsBtCoV/3710 clustered with Bt$\mathrm{CoV} 1 \mathrm{~A}$ (Figure 4). Sequence comparison showed that the $S$ gene of RsBtCoV/3716, derived from $R$. sinicus, showed higher divergence from other strains among the BtCoV 1B group (Supplementary Table S1). Interestingly, the $S$ genes of coronaviruses detected from the same bat family displayed high divergence. The $S$ gene sequences obtained in this study were deposited in GenBank under accession numbers KU343201 to KU343208.

\section{DISCUSSION}

Bats and rodents are both considered important natural reservoirs of zoonotic viruses (Luis et al., 2013). A previous study reported the discovery of paramyxovirus

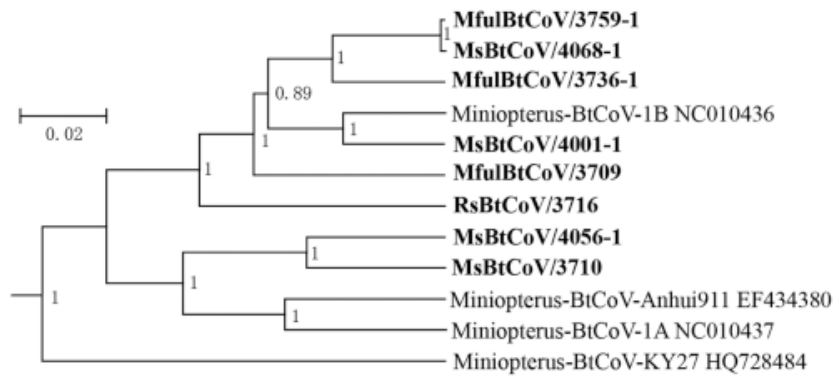

Figure 4. Phylogenetic analysis of bat coronaviruses of BtCoV 1 based on full-length $S$ genes. Eight full-length $S$ gene sequences obtained in this study were aligned with 4 reference $S$ genes and used to construct the phylogenetic tree using MrBayes. Sequences obtained in this study are in bold.
(MojV) in rats (Rattus flavipectus) in the same mineshaft in Mojiang (Wu et al., 2014). Here, focusing on another host, we performed a surveillance of coronaviruses in bats. In contrast to the sole strain MojV detected in rats, we found highly divergent alphacoronavirus strains and two betacoronavirus strains in bats from the same mineshaft. Among the eight known bat coronavirus species, four were detected in the cave. In addition, a new putative coronavirus species was detected in a Hipposideros bat.

Most coronaviruses first replicate in epithelial cells of the respiratory and/or enteric tract. Unapparent enteric infection of animals maintains the virus in the population (Lai et al., 2007). Previous studies have indicated that bats host a large number of viruses, but seldom display clinical symptoms under natural or experimental infection conditions (Baker et al., 2013). In this study, we conducted an 18-month surveillance of bat coronaviruses in an abandoned mineshaft cohabited by six bat species across three families. High infection rates of bat coronaviruses, particularly alphacoronaviruses, were detected in the four sampling periods. More interestingly, we observed a high rate of co-infection with two coronavirus species and interspecies infection with the same coronavirus species within or across bat families. These phenomena may be owing to the diversity and high density of bat populations in the same cave, facilitating coronavirus intra- and interspecies transmissions, which may result in recombination and acceleration of coronavirus evolution. Alphacoronaviruses were found in all six collected bat species. The most frequently detected sequences were related to $\mathrm{BtCoV} 1, \mathrm{BtCoV} \mathrm{HKU} 2$, and $\mathrm{Bt}-$ CoV HKU8, BtCoV HKU10, BtCoV HKU7, and two unclassified alphacoronaviruses were less frequently detected. As previously reported, $\mathrm{BtCoV} 1$ and $\mathrm{BtCoV}$ HKU8 are highly prevalent in Miniopterus species (Chu et al., 2006; Woo et al., 2006; Chu et al., 2008), while BtCoV HKU2 mainly infects Rhinolophus species (Woo et al., 2006; Lau et al., 2007). Due to the overlapping host range and cohabitation, high rates of co-infection with $\mathrm{BtCoV} 1$ and $\mathrm{BtCoV}$ HKU8 in individual bats were detected in Miniopterus species. As BtCoV 1B were detected mainly in Miniopterus bats, it could be speculated that $\mathrm{RsBtCoV} / 3716$ may have been a spillover from Miniopterus bats and adapted to $R$. sinicus through $S$ gene mutation.

Most viral sequences detected had high nt/aa identities with the established coronavirus species, indicating that these viruses had relatively stable genetic evolution. Several identified sequences were homologous to unclassified alphacoronaviruses previously detected in Thailand and Kenya, suggesting that these viruses represent novel groups of alphacoronaviruses (Tong et al., 2009; Gouilh et al., 2011; Wacharapluesadee et al., 2015). Further sequencing of full-length genomes will be helpful to 
determine their taxonomic positions.

Members of the genus Betacoronavirus are divided into four lineages: A, B, C, and D (previously termed groups $2 \mathrm{~A}, 2 \mathrm{~B}, 2 \mathrm{C}$, and $2 \mathrm{D}$ ). Lineage $\mathrm{A}$ includes two human coronaviruses, hCoVs OC43 and HKU1, which are typically associated with common colds. Lineage B includes the highly pathogenic human SARS-CoV and the diverse bat SL-CoVs (WIV1, SHC014, Rp3, HKU1, and others). Lineage $\mathrm{C}$ includes the highly pathogenic human MERS-CoV and several bat MERS-CoV-related coronaviruses (BtCoVs HKU4 and HKU 5). Lineage D only contains coronaviruses discovered in bats $(\mathrm{BtCoV}$ HKU9). In this study, we detected a SL-CoV-related sequence in $R$. affinis. This strain is distantly related to the previously discovered bat SL-CoVs in other Rhinolophus species and represents a new strain of SL-CoVs. Additionally, we detected a new betacoronavirus (RaBt$\mathrm{CoV} / 3740-2$ ) in a $H$. pomona sample that formed a distinct lineage in Betacoronavirus along with several other coronaviruses found in Hipposideros bats (Tong et al., 2009; Quan et al., 2010; Gouilh et al., 2011; Wacharapluesadee et al., 2015). Previous studies have indicated that these coronaviruses in Hipposideros bats are SARS-related and should be considered members of betacoronavirus lineage B (Tong et al., 2009; Quan et al., 2010; Gouilh et al., 2011). Based on the sequence comparison and phylogenetic analysis in this study, we suggest that these coronaviruses found in Hipposideros bats of different countries may represent a novel betacoronavirus lineage (tentatively, lineage E). Considering that the two highly pathogenic human coronaviruses (SARS-CoV and MERS-CoV) in this genus originated from bats (Ge et al., 2013; Lau et al., 2013; Corman et al., 2014), attention should be particularly paid to these lineages of bat coronaviruses.

\section{ACKNOWLEDGMENTS}

This work was jointly funded by the National Natural Science Foundation of China (81290341) and Scientific and Technological Basis Special Project (2013FY113500), and China Mega-Project for Infectious Disease (2014ZX 10004001-003) from the Minister of Science and Technology of the People's Republic of China, and USNIAID (R01AI110964). We are very grateful to Adam Nitido for help in language editing.

\section{COMPLIANCE WITH ETHICS GUIDELINES}

The authors declare that they have no conflict of interest. This study was approved by the Ethics Committee of the Yunnan Institute of Endemic Disease Control and Prevention. All institutional and national guidelines for the care and use of animals were followed.

\section{AUTHOR CONTRIBUTIONS}

ZLS designed and coordinated the study. XYG, YZZ, JHZ, CML, XLY, LJW, BW, YZ, and ZXL collected samples. NW, XYG, WZ, BH, and BL performed molecular studies. XYG and NW analyzed the data. XYG and ZLS drafted the manuscript. All authors read and approved the final manuscript.

Supplementary Table S1 is available on the website of Virologica Sinica: www.virosin.org; link.springer.com/ journal/12250.

\section{REFERENCES}

Anthony SJ, Ojeda-Flores R, Rico-Chavez O, Navarrete-Macias I, Zambrana-Torrelio CM, Rostal MK, Epstein JH, Tipps T, Liang E, Sanchez-Leon M, Sotomayor-Bonilla J, Aguirre AA, Avila-Flores R, Medellin RA, Goldstein T, Suzan G, Daszak P, Lipkin WI. 2013. Coronaviruses in bats from Mexico. J Gen Virol, 94: 1028-1038.

Baker ML, Schountz T, Wang LF. 2013. Antiviral immune responses of bats: a review. Zoonoses Public Health, 60: 104-116.

Bruckova M, McIntosh K, Kapikian AZ, Chanock RM. 1970. The adaptation of two human coronavirus strains (OC38 and OC43) to growth in cell monolayers. Proc Soc Exp Biol Med, 135: 431-435.

Cavanagh D, Britton P. 2012. Virus Taxonomy: Ninth Report of the International Committee on Taxonomy of Viruses. Family Coronaviridae. In: International Committee on Taxonomy of Viruses. Andrew M.Q. King MJA, Eric B. Carstens, and Elliot J. Lefkowitz (eds). Cambridge: Academic Press Elsevier, pp. 770-792.

Chu DK, Peiris JS, Chen H, Guan Y, Poon LL. 2008. Genomic characterizations of bat coronaviruses (1A, 1B and HKU8) and evidence for co-infections in Miniopterus bats. J Gen Virol, 89: 1282-1287.

Chu DK, Poon LL, Chan KH, Chen H, Guan Y, Yuen KY, Peiris JS. 2006. Coronaviruses in bent-winged bats (Miniopterus spp.). J Gen Virol, 87: 2461-2466.

Corman VM, Ithete NL, Richards LR, Schoeman MC, Preiser W, Drosten C, Drexler JF. 2014. Rooting the phylogenetic tree of Middle East respiratory syndrome coronavirus by characterization of a conspecific virus from an African bat. J Virol, 88: 11297-11303.

De Benedictis P, Marciano S, Scaravelli D, Priori P, Zecchin B, Capua I, Monne I, Cattoli G. 2013. Alpha and lineage C betaCoV infections in Italian bats. Virus Genes, 48: 366-371.

de Souza Luna LK, Heiser V, Regamey N, Panning M, Drexler JF, Mulangu S, Poon L, Baumgarte S, Haijema BJ, Kaiser L, Drosten C. 2007. Generic detection of coronaviruses and differentiation at the prototype strain level by reverse transcription-PCR and nonfluorescent low-density microarray. J Clin Microbiol, 45: 1049-1052.

Drexler JF, Corman VM, Wegner T, Tateno AF, Zerbinati RM, Gloza-Rausch F, Seebens A, Muller MA, Drosten C. 2011. Amplification of emerging viruses in a bat colony. Emerg Infect Dis, 17: 449-456. 
Drexler JF, Gloza-Rausch F, Glende J, Corman VM, Muth D, Goettsche M, Seebens A, Niedrig M, Pfefferle S, Yordanov S, Zhelyazkov L, Hermanns U, Vallo P, Lukashev A, Muller MA, Deng H, Herrler G, Drosten C. 2010. Genomic characterization of severe acute respiratory syndrome-related coronavirus in European bats and classification of coronaviruses based on partial RNA-dependent RNA polymerase gene sequences. J Virol, 84: 11336-11349.

Ge XY, Li JL, Yang XL, Chmura AA, Zhu G, Epstein JH, Mazet JK, Hu B, Zhang W, Peng C, Zhang YJ, Luo CM, Tan B, Wang N, Zhu Y, Crameri G, Zhang SY, Wang LF, Daszak P, Shi ZL. 2013. Isolation and characterization of a bat SARS-like coronavirus that uses the ACE2 receptor. Nature, 503: 535-538.

Geldenhuys M, Weyer J, Nel LH, Markotter W. 2013. Coronaviruses in South african bats. Vector Borne Zoonotic Dis, 13: 516-519.

Goes LG, Ruvalcaba SG, Campos AA, Queiroz LH, de Carvalho C, Jerez JA, Durigon EL, Davalos LI, Dominguez SR. 2013. Novel bat coronaviruses, Brazil and Mexico. Emerg Infect Dis, 19: 1711-1713.

Gouilh MA, Puechmaille SJ, Gonzalez JP, Teeling E, Kittayapong P, Manuguerra JC. 2011. SARS-Coronavirus ancestor's foot-prints in South-East Asian bat colonies and the refuge theory. Infect Genet Evol, 11: 1690-1702.

Graham RL, Donaldson EF, Baric RS. 2013. A decade after SARS: strategies for controlling emerging coronaviruses. Nat Rev Microbiol, 11: 836-848.

Hall TA. 1999. BioEdit: a user-friendly biological sequence alignment editor and analysis program for Windows 95/98/NT. Nucleic Acids Symp Ser (Oxf), 41: 95-98.

Huelsenbeck JP, Ronquist F. 2001. MRBAYES: Bayesian inference of phylogenetic trees. Bioinformatics, 17: 754-755.

Irwin DM, Kocher TD, Wilson AC. 1991. Evolution of the Cytochrome-B Gene of Mammals. J Mol Evol, 32: 128-144.

Kusanagi K, Kuwahara H, Katoh T, Nunoya T, Ishikawa Y, Samejima T, Tajima M. 1992. Isolation and serial propagation of porcine epidemic diarrhea virus in cell cultures and partial characterization of the isolate. J Vet Med Sci, 54: 313-318.

Lai MMC, Perlman S, Anderson LJ. 2007. Coronaviridae. In: Fields Virology, Knipe DM, Howley PM (eds). Philadephia: Lippincott Williams \& Wilkins, pp. 1305-1336.

Larkin MA, Blackshields G, Brown NP, Chenna R, McGettigan PA, McWilliam H, Valentin F, Wallace IM, Wilm A, Lopez R, Thompson JD, Gibson TJ, Higgins DG. 2007. Clustal W and Clustal X version 2.0. Bioinformatics, 23: 2947-2948.

Lau SK, Li KS, Tsang AK, Lam CS, Ahmed S, Chen H, Chan KH, Woo PC, Yuen KY. 2013. Genetic characterization of Betacoronavirus lineage $\mathrm{C}$ viruses in bats reveals marked sequence divergence in the spike protein of pipistrellus bat coronavirus HKU5 in Japanese pipistrelle: implications for the origin of the novel Middle East respiratory syndrome coronavirus. J Virol, 87: 8638-8650.

Lau SK, Li KS, Tsang AK, Shek CT, Wang M, Choi GK, Guo R, Wong BH, Poon RW, Lam CS, Wang SY, Fan RY, Chan KH, Zheng BJ, Woo PC, Yuen KY. 2012. Recent transmission of a novel alphacoronavirus, bat coronavirus HKU10, from Leschenault's rousettes to pomona leaf-nosed bats: first evidence of interspecies transmission of coronavirus between bats of different suborders. J Virol, 86: 11906-11918.

Lau SK, Woo PC, Li KS, Huang Y, Tsoi HW, Wong BH, Wong SS, Leung SY, Chan KH, Yuen KY. 2005. Severe acute respiratory syndrome coronavirus-like virus in Chinese horseshoe bats. Proc Natl Acad Sci U S A, 102: 14040-14045.

Lau SKP, Woo PCY, Li KSM, Huang Y, Wang M, Lam CSF, Xu HF, Guo RT, Chan KH, Zheng BJ, Yuen KY. 2007. Complete genome sequence of bat coronavirus HKU2 from Chinese horseshoe bats revealed a much smaller spike gene with a different evolutionary lineage from the rest of the genome. Virology, 367: 428-439.

Lelli D, Papetti A, Sabelli C, Rosti E, Moreno A, Boniotti MB. 2013. Detection of coronaviruses in bats of various species in Italy. Viruses, 5: 2679-2689.

Li W, Shi Z, Yu M, Ren W, Smith C, Epstein JH, Wang H, Crameri G, Hu Z, Zhang H, Zhang J, McEachern J, Field H, Daszak P, Eaton BT, Zhang S, Wang LF. 2005. Bats are natural reservoirs of SARS-like coronaviruses. Science, 310: 676-679.

Luis AD, Hayman DTS, O'Shea TJ, Cryan PM, Gilbert AT, Pulliam JRC, Mills JN, Timonin ME, Willis CKR, Cunningham AA, Fooks AR, Rupprecht CE, Wood JLN, Webb CT. 2013. A comparison of bats and rodents as reservoirs of zoonotic viruses: are bats special? Proc Biol Sci, 280: 20122753.

Macnaughton MR, Madge MH. 1978. The genome of human coronavirus strain 229E. J Gen Virol, 39: 497-504.

Martin DP, Williamson C, Posada D. 2005. RDP2: recombination detection and analysis from sequence alignments. Bioinformatics, 21: 260-262.

Mayer F, von Helversen O. 2001. Cryptic diversity in European bats. Proc Biol Sci, 268: 1825-1832.

Mihindukulasuriya KA, Wu G, St Leger J, Nordhausen RW, Wang D. 2008. Identification of a novel coronavirus from a beluga whale by using a panviral microarray. J Virol, 82: 5084-5088.

Mizutani T. 2001. The mechanism of MHV transcription. Uirusu, 51: 225-236. (In Janpanese)

Pedersen NC, Black JW, Boyle JF, Evermann JF, McKeirnan AJ, Ott RL. 1984. Pathogenic differences between various feline coronavirus isolates. Adv Exp Med Biol, 173: 365-380.

Peiris JS, Lai ST, Poon LL, Guan Y, Yam LY, Lim W, Nicholls J, Yee WK, Yan WW, Cheung MT, Cheng VC, Chan KH, Tsang DN, Yung RW, Ng TK, Yuen KY. 2003. Coronavirus as a possible cause of severe acute respiratory syndrome. Lancet, 361: $1319-1325$.

Poon LL, Chu DK, Chan KH, Wong OK, Ellis TM, Leung YH, Lau SK, Woo PC, Suen KY, Yuen KY, Guan Y, Peiris JS. 2005. Identification of a novel coronavirus in bats. J Virol, 79: 2001-2009.

Quan PL, Firth C, Street C, Henriquez JA, Petrosov A, Tashmukhamedova A, Hutchison SK, Egholm M, Osinubi MO, Niezgoda M, Ogunkoya AB, Briese T, Rupprecht CE, Lipkin WI. 2010. Identification of a severe acute respiratory syndrome coronavirus-like virus in a leaf-nosed bat in Nigeria. MBio, 1. doi: 10.1128/mBio.00208-10.

Shi ZL. 2013. Emerging infectious diseases associated with bat viruses. Science China-Life Sciences, 56: 678-682.

Tang XC, Zhang JX, Zhang SY, Wang P, Fan XH, Li LF, Li G, Dong BQ, Liu W, Cheung CL, Xu KM, Song WJ, Vijaykrishna D, Poon LLM, Peiris JSM, Smith GJD, Chen H, Guan Y. 2006. Prevalence and genetic diversity of coronaviruses in bats from China. J Virol, 80: 7481-7490.

Tong S, Conrardy C, Ruone S, Kuzmin IV, Guo X, Tao Y, Niezgoda M, Haynes L, Agwanda B, Breiman RF, Anderson LJ, Rupprecht CE. 2009. Detection of novel SARS-like and other coronaviruses in bats from Kenya. Emerg Infect Dis, 15: $482-485$.

van Boheemen S, de Graaf M, Lauber C, Bestebroer TM, Raj VS, Zaki AM, Osterhaus AD, Haagmans BL, Gorbalenya AE, Snijder EJ, Fouchier RA. 2012. Genomic characterization of a newly discovered coronavirus associated with acute respiratory distress syndrome in humans. MBio, 3. doi: 10.1128/mBio.00473-12. van der Hoek L, Pyrc K, Jebbink MF, Vermeulen-Oost W, 
Berkhout RJ, Wolthers KC, Wertheim-van Dillen PM, Kaandorp J, Spaargaren J, Berkhout B. 2004. Identification of a new human coronavirus. Nat Med, 10: 368-373.

Wacharapluesadee S, Duengkae P, Rodpan A, Kaewpom T, Maneeorn P, Kanchanasaka B, Yingsakmongkon S, Sittidetboripat N, Chareesaen C, Khlangsap N, Pidthong A, Leadprathom K, Ghai S, Epstein JH, Daszak P, Olival KJ, Blair PJ, Callahan MV, Hemachudha T. 2015. Diversity of coronavirus in bats from Eastern Thailand. Virol J, 12: 57.

Watanabe S, Masangkay JS, Nagata N, Morikawa S, Mizutani T, Fukushi S, Alviola P, Omatsu T, Ueda N, Iha K, Taniguchi S, Fujii H, Tsuda S, Endoh M, Kato K, Tohya Y, Kyuwa S, Yoshikawa Y, Akashi H. 2010. Bat Coronaviruses and Experimental Infection of Bats, the Philippines. Emerg Infect Dis, 16: 1217-1223.

Woo PC, Lau SK, Chu CM, Chan KH, Tsoi HW, Huang Y, Wong BH, Poon RW, Cai JJ, Luk WK, Poon LL, Wong SS, Guan Y, Peiris JS, Yuen KY. 2005. Characterization and complete genome sequence of a novel coronavirus, coronavirus HKU1, from patients with pneumonia. J Virol, 79: 884-895.

Woo PC, Lau SK, Lam CS, Lau CC, Tsang AK, Lau JH, Bai R, Teng JL, Tsang CC, Wang M, Zheng BJ, Chan KH, Yuen KY. 2012a. Discovery of seven novel Mammalian and avian coronaviruses in the genus deltacoronavirus supports bat coronaviruses as the gene source of alphacoronavirus and betacoronavirus and avian coronaviruses as the gene source of gammacoronavirus and deltacoronavirus. J Virol, 86: 3995-4008.

Woo PC, Lau SK, Li KS, Poon RW, Wong BH, Tsoi HW, Yip BC, Huang Y, Chan KH, Yuen KY. 2006. Molecular diversity of coronaviruses in bats. Virology, 351: 180-187.

Woo PCY, Lau SKP, Huang Y, Yuen KY. 2009. Coronavirus Diversity, Phylogeny and Interspecies Jumping. Exp Biol Med (Maywood), 234: 1117-1127.

Woo PCY, Lau SKP, Li KSM, Tsang AKL, Yuen KY. 2012b. Genetic relatedness of the novel human group $\mathrm{C}$ betacoronavirus to Tylonycteris bat coronavirus HKU4 and Pipistrellus bat coronavirus HKU5. Emerg Microb Infect, 1: e35.

Wu ZQ, Yang L, Yang F, Ren XW, Jiang JY, Dong J, Sun LL, Zhu YF, Zhou HN, Jin Q. 2014. Novel Henipa-like Virus, Mojiang Paramyxovirus, in rats, China, 2012. Emerg Infect Dis, 20: 1064-1066.

Yuan J, Hon CC, Li Y, Wang D, Xu G, Zhang H, Zhou P, Poon LL, Lam TT, Leung FC, Shi Z. 2010. Intraspecies diversity of SARS-like coronaviruses in Rhinolophus sinicus and its implications for the origin of SARS coronaviruses in humans. J Gen Virol, 91: 1058-1062.

Zaki AM, van Boheemen S, Bestebroer TM, Osterhaus AD, Fouchier RA. 2012. Isolation of a novel coronavirus from a man with pneumonia in Saudi Arabia. N Engl J Med, 367: 1814-1820. 